\title{
Culto cívico dos mortos e escrita da história: reflexões sobre a obra de Fernando Catroga*
}

Douglas Attila Marcelino**

Resumo: Partindo da existência de diferentes tradições teóricas de estudo das formas de lidar com a morte, este artigo analisa as reflexões produzidas pelo historiador português Fernando Catroga, indicando como o tema ganha relevância para a teoria da história por suas interrogações sobre as relações entre os ritos mortuários e a historiografia. Destaca-se, principalmente, o diálogo com tradições determinadas no campo da sociologia e da antropologia, que permitem retomar questionamentos filosóficos mais profundos sobre os temas $\mathrm{da}$ morte e da historicidade numa perspectiva atenta às especificidades do olhar histórico e sua vinculação com uma forma de refletir sobre as próprias experiências considerando as respostas fornecidas a problemas de natureza existencial humana pelos homens de outras épocas ou culturas. Nessa perspectiva, além da historicidade, o problema da alteridade ganha relevância central para a historiografia, entendida como uma entre outras práticas coletivas de ritualização do tempo, caracterizada pela especificidade de sua vocação crítica. Palavras-chave: Culto dos mortos. Práticas cívicas. Historicidade. Memória. Historiografia.

\footnotetext{
"Esta pesquisa foi financiada pelo CNPq.

** Doutor em História Social pela Universidade Federal do Rio de Janeiro. Professor Adjunto de Teoria da História e História da Historiografia do Departamento de História da Universidade Federal de Minas Gerais. E-mail: douglasattila@ gmail.com
}

Anos 90, Porto Alegre, v. 23, n. 44, p. 305-331, dez. 2016 


\section{Introdução}

Entre as necessidades existenciais do homem, que conformam certas constantes antropológicas indicadas em estudos diversos do campo das humanidades, ressalta-se a elaboração de práticas culturais de simbolização da morte, impulsionadas pelo desejo de eternização a partir da criação de ritos que tendem a escamotear a corrupção do tempo e permitir, por meio do trabalho de luto, o reestabelecimento dos laços sociais fragilizados pelo caráter trágico da perda. A ritualização da morte e o desejo de controle sobre sua imponderabilidade através da invenção e do uso de códigos culturais específicos, que conferem historicidade aos ritos de passagem e tantas páginas têm rendido aos antropólogos, se chocam com sua onipresença na história humana, estimulando a produção de um amplo conjunto de estudos que transitam entre campos como os da filosofia, da antropologia, da sociologia, da psicanálise, da semiolinguística e da história.

No que se refere ao diálogo com a tradição filosófica de matriz heideggeriana, ao lado da sua valorização pela ênfase na historicidade, interrogações têm sido formuladas sobre o modo como a centralidade conferida à dimensão ontológica dificultaria considerar que qualquer experiência da morte deve ser compreendida a partir dos mecanismos intersubjetivos por meio dos quais se estruturam historicamente as diversas formas de imaginário da morte. Nesse caso, ganham mais relevo não apenas as dimensões ética e política, conforme apontaria toda uma vertente valorizadora da preocupação com a morte do outro em detrimento da relação antecipatória que estabeleço com a minha morte, mas também a histórica, já que a relevância dada à existência humana como experiência coletiva enfatiza o fundamento linguístico dessa relação com o outro, a partir da qual os desejos, expectativas e anseios em relação à morte assumem configurações específicas dentro de um momento histórico determinado ${ }^{1}$. A suposta menor valorização das dimensões ética e política das interrogações heideggerianas, por outro lado, já foi identificada com o não tratamento do trabalho de luto, que ganharia importância nas reflexões de Paul Ricoeur 
e Jörn Rüsen, estimulando a comparação entre o estabelecimento de práticas culturais para lidar com a perda e a própria escrita da história ${ }^{2}$.

A abertura do campo de reflexões aqui ressaltado para a semiolinguística permitiu falar também de uma "poética da ausência” por relação ao caráter supostamente estruturado do sistema de signos inventados pelo homem para lidar com a morte, conforme se poderia perceber, por exemplo, pela existência de uma verdadeira "linguagem cemiterial", caracterizada pela relação lógica de significação entre os símbolos funerários, com seus efeitos de presença e de dissimulação da perda (CATROGA, 1999; URBAIN, 1989, 1978) ${ }^{3}$. O estudo das práticas simbólicas que conferem sentido à morte, igualmente alimentados pelo potencial da análise linguística, se voltaram ainda para uma abordagem poética do elogio como gênero literário. Quando conjugada com uma preocupação efetivamente histórica de identificação das invenções e transformações das figurações e dos topoi constitutivos do gênero, esse tipo de análise pareceu frutífera, inclusive, pela possibilidade de aproximação com os estudos voltados para uma poética da historiografia, tendo em vista o aumento do interesse nesse sentido desde as últimas décadas do século passado (LORAUX, 1994; BONNET, 1997) ${ }^{4}$. Os estudos sobre a antiga "arte da memória", por outro lado, remetem ainda ao plano da retórica, gerando reflexões igualmente relevantes sobre a historiografia, principalmente no que diz respeito à revalorização do papel duradouro dos tratados ciceronianos e outros textos canônicos nas técnicas de encenação discursiva da escrita histórica ${ }^{5}$.

Paralelamente a essa tradição, na qual o tema da memória se interliga com o das antigas mnemotécnicas, um conjunto de estudos tem se voltado para aquilo que Aleida Assmann chamaria da memória como potência, configurando uma perspectiva densamente histórica e antropológica, na qual temas como os da recordação, da imaginação e da identidade seriam fundamentais. Se considerarmos, como a autora, que "[...] a memória cultural tem como seu núcleo antropológico a memoração dos mortos”, tendo em vista que o culto daqueles que se foram é "[...] a mais antiga e difundida forma de recordação social que une vivos e mortos" 
(ASSMANN, 2011, p. 37), ficará clara a valorização de uma dimensão fortemente sócio-histórica, na qual as questões de natureza antropológica se relacionam com os temas do imaginário e das práticas culturais de ritualização do poder e do tempo ${ }^{6}$.

Além da indicação de diferentes tradições teóricas do estudo das práticas culturais de ritualização da morte, é possível analisá-las numa perspectiva mais efetivamente diacrônica, na qual suas transformações seriam percebidas como parte de um complexo e multifacetado processo de crescente laicização dos discursos, marcado por momentos importantes, como a invenção da oração fúnebre ateniense e a constituição do elogio acadêmico como novo gênero a partir do Enciclopedismo do século XVIII (LORAUX, 1994; BONNET, 1997). Além das novas demandas relativas à temporalidade que marcaram uma crescente secularização do horizonte de expectativas, tal processo se relacionaria com uma tendência à maior racionalização e uso político das práticas discursivas e rituais de monumentalização da morte, aspecto que, tal como indicaram autores como Fernando Catroga e Reinhart Koselleck, caracterizou igualmente a formação do moderno conceito de história (CATROGA, 1999, 2009, 1998, 2010; KOSELLECK, 2011a, 2011b, 2006). O importante a ressaltar é que, para além do recorte diacrônico, tal perspectiva permite pensar um campo de reflexão atento às demandas relativas à temporalidade e ao poder que atravessam práticas rituais diversas, entendendo o campo da história da historiografia por sua relação com discussões mais amplas sobre as condições de possibilidade da produção de sentido sobre o passado.

Embora relacionado com esse universo de discussões, este artigo tem um objetivo muito mais limitado, concentrando-se nas interrogações produzidas sobre as relações entre os ritos de culto dos mortos e a escrita da história presentes nos textos de Fernando Catroga. Apesar da importância das reflexões elaboradas pelo historiador português no campo da teoria da história, expressa na produção de um conjunto extenso de publicações, suas obras não têm sido objeto de análises mais aprofundadas dentro da historiografia brasileira. No caso específico do tema aqui enfocado, torna-se importante perceber seu diálogo com as relações estabelecidas entre a historiografia e os rituais de culto dos mortos presentes nos textos 
de autores como Michel de Certeau e Paul Ricoeur, os quais figuram como interlocutores fundamentais do historiador português. As apropriações feitas das ideias desses autores, por outro lado, foram singulares, amparando-se também numa interpretação específica sobre a Modernidade e sobre o lugar do religioso nos dias atuais (o problema extremamente complexo de suas imbricações com o político na época contemporânea).

Nos limites deste artigo, poderemos explorar algumas dessas interpretações, sugestivas do modo como os diálogos e as ideias formuladas por Catroga são potencialmente críticas às concepções heideggerianas sobre o tema da morte, tal como aconteceria também nas reflexões de Paul Ricoeur, como já indicado. O próprio tratamento das práticas de culto dos mortos e de sua relação com certo fundamento ritual da escrita histórica, portanto, conduzem a questionamentos centrais do ponto de vista da teoria da história, que relativizam as interpretações voltadas para o tema da morte numa perspectiva que tende a manter traços metafísicos, pouco atentando à historicidade a partir da qual se estabelecem os condicionantes por meio dos quais qualquer relação com o fim da vida pode ser sentida, ou mesmo imaginada. Trata-se, em última instância, da constituição de uma leitura com densidade histórica e antropológica, que confere um lugar privilegiado à historiografia como campo de interrogação sobre as formas pelas quais os homens de diferentes culturas humanas lidaram com a própria finitude constitutiva da existência, estabelecendo práticas rituais historicamente determinadas, cuja análise não conduz à formulação de respostas acerca de um sentido do "ser" em sua verdadeira autenticidade.

\section{Escrita histórica e ritos de culto dos mortos dentro das novas afetividades do século XVIII}

As comparações estabelecidas por Fernando Catroga entre a escrita histórica e as práticas de ritualização da morte estão relacionadas com a tentativa de pensar suas especificidades dentro das novas formas de sensibilidade e afetividade que despontaram, sobretudo, a partir da segunda metade do século XVIII (CATROGA, 
1999). As reflexões do historiador português nesse plano ganharam mais expressividade a partir de sua tese doutoral, Militância laica e descristianização da morte em Portugal (1865-1911), defendida em 1988 , embora as preocupações com o tema estejam relacionadas com pesquisas anteriores sobre o positivismo em Portugal'. Tratavase também de uma forma particular de estudar o republicanismo português, conforme ressaltou António Pita (2015, p. 62-63), assunto que, paralelamente ao dos ritos mortuários, acabou gerando uma extensa bibliografia ${ }^{8}$. As investigações de Catroga sobre o pensamento de Antero de Quental, por outro lado, não deixaram de guardar vínculos com o tema da morte e das "raízes metafísicas" de suas ideias 9 .

Esse conjunto de pesquisas deu origem a um olhar eminentemente histórico sobre o tema da morte, sempre inserido numa perspectiva mais geral acerca das atitudes perante a morte na Europa cristã, mas com estudos mais sistemáticos sobre o período que se seguiu à "revolução romântica" dos cemitérios e ao fortalecimento do republicanismo em Portugal ${ }^{10}$. Nesse caso, mesmo estudos mais específicos não deixaram de trazer reflexões sobre os sentidos existenciais das práticas mortuárias, conferindo densidade teórica às interrogações produzidas. Sem desconsiderar as singularidades das novas formas de ritualização do luto, Catroga as compreenderia por sua relação com os desejos de eternização característicos do homem em sua condição de ser finito e marcado pela consciência de sua destinação à morte, enfatizando sua historicidade por meio de um olhar antropológico atento à dimensão coletiva dos ritos de recordação ${ }^{11}$.

Esse tipo de interrogação não conduziria a um tratamento do ser em sua temporalidade fundamental, mas para práticas simbólicas cuja dissimulação da finitude estaria ligada a exigências mais profundas de enraizamento do homem em totalidades genealógicas imaginadas, tendo em vista que os anseios afetivos e identitários de pertencimento a coletivos e de transmissão de sua herança são condições fundamentais da existência. As práticas simbólicas de tradução ritual do luto, nessa perspectiva, ficariam condicionadas às transformações históricas, sofrendo as implicações modernas do 
processo de secularização da escatologia cristã, pois a tendência à transferência dos desejos e esperanças de salvação para o mundo terreno sobrevalorizaria a memória histórica e impulsionaria a elaboração de leituras mais racionalizadas do passado, fomentando, assim, formas diversas de ritualização da história, dentre as quais a historiografia ${ }^{12}$.

Mais do que qualquer outro, o culto romântico dos mortos manifestaria essas novas demandas de monumentalização, caracterizadas também por uma sensibilidade temporal de fundo historicista, com seus anseios de perfectibilidade, suas expectativas acerca de um tempo progressivo, irreversível e cumulativo. Trata-se, portanto, de toda uma forma de racionalidade e afetividade que, além de transformar as práticas rituais já existentes, como a eleição das sepulturas como lugar fundamental de recordação, a maior dramatização da perda e a personalização dos grandes funerais nacionais, fortaleceria o sentido político da memória, aumentando as disputas e conflitos pelo monopólio dos suportes e ritos de eternização pela lembrança (CATROGA, 1999, p. 28 et seq.). Isto porque, na leitura de Catroga, quanto mais extensa a coletividade imaginada, mais sujeita ficaria à manipulação e aos mecanismos político-ideológicos, embora o uso mais racionalizado do passado, que remete para recursos mais artificiais como a "fabricação" e a "invenção", não fosse compreendido como uma total ruptura em relação às formas mais espontâneas de construção de memória em suas dimensões comunitárias e afetivas.

A preocupação com a raiz metafísica dos impulsos que impelem o homem a cultuar os mortos, tendo em vista sua natureza como ser construtor de cultura e de memória, tornaria Catroga sensível, inclusive, aos fundamentos familiares das novas práticas simbólicas de exaltação dos "grandes homens" que alcançaram relevância a partir da segunda metade do século XVIII ${ }^{13}$. Na verdade, não apenas haveria certa continuidade entre o culto familiar dos mortos e a constituição de um novo "imaginário do Panteão", mas a própria sepultura seria um símbolo referido à perpetuação das famílias, permitindo exemplificar a continuidade existente entre as novas práticas de visita aos cemitérios e as comemorações políticas: 
Culto cívico dos mortos e escrita da história:...

Defende-se assim que, mesmo à escala familiar da 'visita a cemitério', é possível surpreender as características que, numa evidente transferência analógica, as comemorações políticas de raiz tanatológica explicitarão de uma maneira ainda mais evidente. A comemoração é herdeira, não só da solenidade da cerimônia pública de elogio e de menção de um nome, como implica a sacralização do evocado, desenrolando-se, em similitude com a sua matriz - o ato religioso do culto dos mortos -, num rito eficaz para a memória e, principalmente, para o destino dos vivos (CATROGA, 1999, p. 23).

Note-se que, num plano mais profundo, não se trata apenas de considerar a continuidade entre práticas coexistentes em termos históricos, mas de uma compreensão dos fundamentos culturais dos mecanismos de enraizamento em formações coletivas por meio de construções simbólicas e imaginárias. Até porque a noção de família remeteria, em última instância, àquela de pátria, tomada em outro texto do autor como uma

[...] espécie de alfa fundador de todas as filiações étnico-culturais e políticas, matriz que age como um apelo, ou melhor, como uma herança, cujo dever de transmissibilidade acena para contornos escatológicos (CATROGA, 2008, p. 21).

Presente ainda nos poemas homéricos como forma originária de identificação coletiva, quando resguardava um sentido predominantemente relacionado à população e ao território, a noção de pátria deveria ser diferenciada de outras como patriotismo, nação e nacionalismo justamente considerando o maior ou menor grau de institucionalização e uso político dessas construções imaginadas em relação às demandas afetivas e identitárias do homem pela homogeneização dos sentimentos de pertença ${ }^{14}$.

A pressuposição de certa continuidade entre o culto familiar dos mortos e as comemorações políticas de natureza tanatológica deve ser compreendida em sua ligação com a forma relacional e não 
dicotômica de tratamento de pares conceituais como recordação e comemoração, memória individual e memória coletiva, ou mesmo história e memória. Nesse caso, o afastamento da tendência cientificista presente em determinadas obras de Maurice Halbwachs, propensas a certa reificação da "memória coletiva", não impediria Catroga de entender a recordação sempre como um ato de alteridade, que toma de empréstimo formas públicas de produção narrativa de sentido, dialogando com a perspectiva de Paul Ricoeur, para quem a memória do indivíduo deveria ser entendida como um fenômeno relacional e intersubjetivo (CATROGA, 2009, p. 13-14). Daí a importância da linguagem pública do rito, fenômeno que, por sua natureza memorial, guardaria as mesmas características pragmáticas e normativas de outras práticas culturais dissimuladoras da morte, como a própria historiografia, também caracterizada por suas funções existenciais de distinção, filiação e identificação (CATROGA, 2009, p. 24 et seq.).

Trata-se também da valorização de uma tradição sociológica para a qual os ritos, como condicionantes antropológicos fundados na natureza do homem como animal simbólico, possuiriam sempre uma função "instituinte de sociabilidades", sacralizando e sancionando um estado de coisas por meio da naturalização das diferenças, que se tornam duráveis porque reconhecidas. A releitura proposta por Pierre Bourdieu da noção de "rito de passagem", de Arnold van Gennep, acentuando sua dimensão de construção simbólica de uma ordem social, permitiu a Fernando Catroga entender a própria historiografia como prática cultural com uma função de "rito de instituição"15.

É possível perguntar se esse tipo de concepção não guardaria relação com as próprias interpretações da Modernidade presentes nas obras de Fernando Catroga. Não obstante tenha partilhado de um conjunto de leituras que apontaram a matriz judaico-cristã do processo de secularização, ressaltando os fundamentos teológicos que dariam origem às filosofias da história do século XVIII, Catroga formularia uma crítica relativamente matizada aos ideais universalistas então inaugurados: 
E não basta dizer - numa espécie de interiorização da culpa histórica - que o universalismo subjacente às filosofias da história só serviu de capa encobridora da visão eurocêntrica e dos seus projetos de dominação de outros povos. Se é certo que esta denúncia tem toda a pertinência, terão de ser equacionados, igualmente, os efeitos decorrentes da outra face destes valores, já que será precisamente a partir da sua raiz crítica e das suas promessas de universalismo não cumpridas (exemplo: os direitos humanos) que os dominados encontraram armas para contestarem os dominantes e para fundamentarem a sua própria identidade (CATROGA, 2006b, p. 30).

Além disso, Catroga buscou um distanciamento importante em relação aos diagnósticos de autores como Carl Schmitt e Ernst Kantorowicz, por exemplo. Em seu volumoso estudo sobre as singularidades das relações entre o religioso e o político em diferentes países do mundo Ocidental, o historiador português procurou estabelecer uma interpretação equilibrada em relação às visões otimistas e pessimistas acerca do processo de secularização (que advogavam uma perda ou regresso do religioso), contrapondo-se às leituras que "[...] sublinharam o fato de a centração imanentista e secular das raízes do poder ter sido uma vitória equívoca”, tendo em vista a transferência dos conceitos da teologia católica para o interior da teoria política e jurídica do Estado Moderno (CATROGA, 2006a, p. 101). Referindo-se às obras de Schmitt e Kantorowicz, Catroga ressaltaria que "[...] esta contaminação exige matizações e impõe que se releve o movimento inverso, porque também houve intercâmbios entre o teológico e o jurídico-político”. Além disso, seria preciso "[...] saber se a teologia cristã mais não é, em última análise, 'qu’une politique qui s'est desarrimée”" (CATROGA, 2006a, p. 102).

Nesse caso, suas reflexões parecem próximas das de Hannah Arendt, autora frequentemente citada pelo historiador português, e que também argumentou acerca do sentido político da religião cristã, pelo menos desde sua romanização até uma suposta maior separação entre o político e o religioso na Modernidade, tendo em vista uma categorização assemelhada do processo de secularização 
não apenas como uma transferência de categorias teológicas para o mundo terreno, mas como uma maior separação entre esses dois campos (ARENDT, 2005, p. 69-126). Na leitura de Hannah Arendt, Santo Agostinho teria sido o "maior teórico da política cristã", cuja percepção de que alguma vida política deveria existir mesmo em condições de inocência ou santidade se expressaria na pressuposição de que "[...] mesmo a vida de santo é uma vida em comum com os outros homens" (ARENDT, 2005, p. 108). Nessa perspectiva, o arrefecimento dos fundamentos antipolíticos do "cristianismo primitivo" teria permitido que a conjugação entre autoridade da Igreja e poder da realeza existisse por longo período na história ocidental (ARENDT, 2005, p. 127-187) ${ }^{16}$.

\section{A sempre iminente irrupção do novo}

Assim como tinha feito no diagnóstico sobre a Modernidade, Fernando Catroga também buscaria estabelecer leituras mais matizadas sobre a elaboração de novas práticas rituais para lidar com a morte nas sociedades ocidentais contemporâneas, buscando dialogar com autores que permitiriam considerar as especificidades das transformações que se intensificaram no período mais recente sem caracterizá-las pela ausência. Nesse sentido, a abertura dada à "[...] sempre iminente irrupção do novo" (CATROGA, 2009, p. 257) faria com que Catroga conjugasse à crítica às filosofias da história e às formas novas de vivência da temporalidade da época recente um olhar atento ao surgimento de práticas memoriais que são, na verdade, correlatas à pluralidade de mundos e de experiências que caracterizam as sociedades contemporâneas ${ }^{17}$. Assim, na sua leitura, menos do que uma "desritualização ou desmemorização", talvez estivéssemos experimentando "uma ainda pouco perceptível afirmação de novos ritos e novas formas de vivenciar e socializar memórias", tendo em vista a pluralidade de mundos e de tempos sociais que acompanham a perda de monopólio dos meios de memória por parte de grupos que anteriormente funcionavam como guardiões da tradição (como a Igreja, o Estado, as escolas, entre outros) (CATROGA, 2009, p. 31) ${ }^{18}$. 
É nesse sentido que se pode compreender seu diálogo com autores como Joël Candau, cujas preocupações acerca das complexas relações entre as lembranças individuais e o que chamaria de metamemória visavam impedir tanto um atomismo social extremo, quanto um uso pouco pertinente da noção de memória coletiva (CANDAU, 2011, 1996). A fundamentação antropológica do olhar de Candau, atento aos condicionantes sociais que, por meio da linguagem, impediriam entender as recordações do indivíduo pensando-o isoladamente, estabeleciam também os limites do que chamaria de "retóricas holistas" como fórmulas conceituais elaboradas no momento de constituição das ciências sociais, marcado pela reificação e entificação de categorias que se mostrariam cada vez mais frágeis teoricamente. E foi justamente essa preocupação antropológica que lhe permitiu criticar a superestimação da crise atualmente experimentada nos planos da memória e da temporalidade, sem deixar de ressaltar a pertinência de elementos presentes nos vários diagnósticos recentes, devidamente sumarizados pelo autor (CANDAU, 2011, p. 181 et seq.).

Com efeito, as reflexões de Catroga sobre a sempre iminente irrupção do novo podem ser aproximadas das interrogações de Candau acerca da dificuldade atual de realização plena do luto em relação às formas anteriores de vivência de memórias ou, nas suas palavras, sobre a necessidade de "[...] aceitar perder o antigo para que o novo possa aparecer” (CANDAU, 2011, p. 194). Para Candau, uma supervalorização da perda, além de configurar um discurso incapaz de lidar com as faltas e ausências que marcam a incompletude de qualquer presente histórico, tenderia a contribuir para acentuar a crise diagnosticada. Assim, contrariamente aos lamentos e temores sobre o fim da memória e da tradição, seria importante perceber que certa projeção de passado, presente e futuro constitui uma condição inexorável de qualquer sociedade, ressaltando que "[...] hoje é diferente de ontem como ontem diferia de antes de ontem, mesmo que seja incontestável que as mudanças se acelerem" (CANDAU, 2011, p. 193).

Se esta leitura parece mais próxima da estabelecida por Catroga, cabe ressaltar também que ela não é incompatível com as interpretações de Hannah Arendt já mencionadas, tendo em vista que sua 
crítica às filosofias finalistas da história produzidas na Modernidade não impediria o entendimento daquela como um momento em que a imprevisibilidade do novo pode se manifestar, conforme se perceberia na leitura sobre as revoluções francesa e norte-americana (ARENDT, 2011). A abertura ao imprevisto, seja no presente ou no passado, parece manter ligação com a busca de um olhar mais relacional no modo de lidar com certas categorias, que também encontramos em Arendt e que talvez ajude a explicar a atenção de Candau e Catroga ao caráter mais altamente diferenciado das sociedades contemporâneas, já que esta mudança vem acompanhada da assunção do papel de sujeitos por grupos até então sem quaisquer acessos aos mecanismos de perpetuação na memória social.

\section{Diálogos com Michel de Certeau e Paul Ricoeur}

A partir do questionamento mais geral sobre as formas diversas de ritualização da história, Fernando Catroga retomaria as comparações que Michel de Certeau já havia estabelecido entre a historiografia e o gesto de sepultamento. Tal comparação, assim como a compreensão dessas práticas rituais por sua ligação com as noções de dívida e herança, permitem ressaltar a relevância do tema na formulação de interrogações sobre o sentido da escrita histórica, tendo em vista questionamentos teóricos mais profundos acerca do próprio estatuto desta forma específica de conferir sentido ao passado. Torna-se importante perceber, nesse caso, que a retomada da comparação que Michel de Certeau havia estabelecido entre a escrita da história e o rito de sepultamento foi feita por Fernando Catroga referindo-se à apropriação que Paul Ricoeur havia elaborado da obra do historiador francês ${ }^{19}$.

De fato, além da remissão aos fundamentos existenciais da historiografia como forma de exorcização da morte, sua interpretação parecia aproximar-se da ênfase dada por Ricoeur à escrita histórica como exercício do luto na sua dimensão de assimilação da perda que atua performativamente, abrindo um campo de possibilidades e de projetos de futuro a partir do lugar conferido àqueles que se 
foram (RICOEUR, 2000, p. 449-502). Tratava-se, em Ricoeur, de uma retomada das formulações de Michel de Certeau em contraposição à ontologia fundamental heideggeriana e sua caracterização do sentido último do Dasein como "ser-para-a-morte". Nesse caso, o trabalho de luto indicado na "operação historiográfica" fundamentaria uma ontologia do "ser-contra-a-morte", pela qual a historiografia não corresponderia a um nível menos autêntico de temporalidade, mas a uma forma narrativa veiculadora de expectativas de futuro por meio de interrogações sobre as potencialidades perdidas nas experiências do passado (RICOEUR, 2000, p. 480 et seq.) ${ }^{20}$.

Também as noções de dívida e herança, fundamentais para pensar a relação entre a representação histórica e outros ritos de recordação, foram mencionadas por Catroga a partir das reformulações presentes na obra de Ricoeur, cuja interpretação dos textos de Heidegger e Michel de Certeau seriam singulares ${ }^{21}$. Apesar do sentido mais próximo ao da noção de dívida elaborada por Certeau, Ricoeur já havia contrabalançado a ênfase dada à presença do passado no presente como marca de uma ausência ou diferença pela valorização do caráter positivo da vida como tendo-sido, reconsiderando o presente do passado como herança de potencialidades (RICOEUR, 2010, p. 252 et seq.). Além disso, Fernando Catroga definiria a historiografia como forma de re-presentificação, enfatizando a "representação histórica" como meio de dar futuros ao passado e fazendo lembrar a valorização do vivido e do sentido transformador da história presentes em Ricoeur. A noção de representificação, por um lado, remetia à fórmula ricoeuriana de representância, estabelecendo também um diálogo crítico com as teses derivadas do chamado linguistic turn e reconhecendo o fundamento narrativo da historiografia sem reduzi-la aos componentes formais da escrita (CATROGA, 2010b, p. 37) ${ }^{22}$. Por outro lado, acentuava sua dimensão memorial, destacando-a também como uma "poética da ausência”, que re-presentifica o que já não mais existe (CATROGA, 2010b, p. 36).

Da mesma forma que, para o historiador português, a "[...] historiografia estuda o passado que já foi vida” (CATROGA, 2010b, p. 37), para o filósofo francês, 
[...] o historiador não se defronta apenas com mortos, para os quais constrói um túmulo escriturário; ele não se empenha apenas em ressuscitar viventes de antigamente, que já não existem, mas que existiram; ele se dedica a re-apresentar ações e paixões (RICOEUR, 2000, p. 501). ${ }^{23}$

Vale ressaltar, nesse caso, que a própria comparação feita por Catroga entre a historiografia e os símbolos funerários se fundamentaria numa leitura destes últimos que não remetia apenas à morte, mas também à vida:

[...] o símbolo funerário é metáfora de vida e convite a uma periódica ritualização unificadora; ele é para ser vivido e para ajudar a viver, oferecendo-se assim como um texto, cuja compreensão mais afetiva (a dos entes queridos) mobiliza, antes de mais, toda a subjetividade do sobrevivente (CATROGA, 1999, p. 22).

Seria possível, nesse caso, fazer analogias entre a retomada do tema da morte nos últimos escritos de Paul Ricoeur, marcada por sua valorização do imaginário e dos sentidos coletivos dados à perda do outro, com as críticas de Catroga a qualquer pressuposição de inautenticidade dos ritos coletivos que, em sua devida historicidade, configuram práticas de tradução da experiência do luto (RICOEUR, 2012, p. 1-51; CRÉPON, 2013). É interessante notar, no caso do filósofo francês, que mais de um autor já identificou no tema da luta contra certo imaginário da morte o fundamento central de $L a$ mémoire, l'histoire, l'oubli, que retomava de escritos anteriores um diálogo crítico com a tendência supostamente solipsista presente na ontologia fundamental heideggeriana (WORMS, 2013; CRÈPON, 2013 , p. 88 ${ }^{24}$. Na verdade, o próprio Catroga ressaltaria a subvalorização da memória e do político na ontologia heideggeriana, contrapondo-a à filosofia política de Hannah Arendt (CATROGA, 2009, p. 17 et seq.). Se considerarmos, por outro lado, que Michel de Certeau, quando estabeleceu uma analogia entre a escrita histórica e o gesto de sepultamento, também se referia à morte do outro (o 
próprio passado), conferindo um sentido etnológico à historiografia como forma de uma sociedade lidar com a própria alteridade, talvez fique mais clara a interlocução estabelecida por Fernando Catroga com o historiador francês ${ }^{25}$.

De fato, tratava-se, em Michel de Certeau, de uma comparação da escrita histórica com ritos de natureza coletiva, estruturados em torno de uma linguagem referida ao passado, por meio da qual as expectativas em relação ao futuro ganhariam significado, permitindo ao homem configurar o tempo e abrir um campo de possibilidades de ação no presente. A forma de lidar com a morte, portanto, remetia fundamentalmente para a relação com o outro, somente possível por meio de mecanismos intersubjetivos a partir dos quais qualquer desejo ou anseio em relação à natureza do homem como ser finito poderia adquirir sentido. Tal como na leitura lacaniana da psicanálise, que tanto marcou sua formação, esses questionamentos pareciam ultrapassar qualquer plano ontológico para tornarem-se mais próximos ao campo da ética (e, de certa forma, da própria política, aproximando-se assim das questões colocadas por Emmanuel Levinas e pelo próprio Ricoeur sobre o imaginário da morte) (LACAN, 1997; CERTEAU, 1975; RICOEUR, 2012; LEVINAS, 1993; DREIZIK, 2014). A retomada do historiador francês por Fernando Catroga, portanto, também pode ser interpretada como uma leitura crítica em relação à busca de um tratamento do tema da morte que traz consigo implicações importantes para a historiografia, tendo em vista a tendência de desconsiderar sua função como prática que, possuindo também um sentido de natureza ritual, deveria fazer da relação com o outro o fundamento de sua própria existência (por exemplo, buscando reconstituir as formas específicas e historicamente determinadas de imaginar ou sentir a presença da morte, tal como vividas pelos homens do passado, principal modo por meio do qual poderíamos relativizar nossas próprias experiências). 


\section{Considerações finais}

O estudo das diferentes práticas culturais de culto dos mortos envolve tradições e campos disciplinares diversos, os quais, às suas diferentes maneiras, refletem sobre as formas estabelecidas pelo homem para lidar com a inexorabilidade de sua própria historicidade, elaborando ritos e símbolos que, dissimulando o caráter trágico da perda, parecem sugestivos dos anseios de eternidade e permanência no tempo que configuram constantes encontradas nas mais diferentes sociedades. Ao tratar do tema numa perspectiva histórica, Fernando Catroga não apenas buscou atentar para a singularidade das diversas formas de imaginar e experimentar a morte, mas indicou sua relevância para a reflexão teórica acerca das próprias especificidades da historiografia como forma de dar sentido ao passado, dialogando com um conjunto de autores importantes por chamarem a atenção não apenas para questões filosóficas mais gerais, mas também para os fundamentos sociológicos e antropológicos que conferem àquela prática um sentido próximo ao dos ritos que, funcionando como mecanismos de distinção, instituem e sancionam, nos planos do simbólico e do imaginário, uma determinada ordem social.

Por outro lado, sua retomada das analogias elaboradas por Michel de Certeau entre os ritos de sepultamento e a escrita da história, ao aproximar-se das interpretações produzidas por Paul Ricoeur acerca das obras do historiador francês, pode ser compreendida como uma forma de diálogo crítico com tradições filosóficas que, buscando definições acerca do verdadeiro sentido do "ser", tenderam a estabelecer respostas de natureza metafísica para o tema da morte. Sua perspectiva, nesse caso, não parece desconsiderar toda a relevância da reflexão heideggeriana para pensar o tema da historicidade, mas sugere que um estranhamento em relação às formas de experimentação da morte configuradas em nosso próprio tempo pressupõe um olhar atento ao modo como os homens de outras épocas ou culturas forneceram respostas diferenciadas para essa que parece uma constante inevitável da vida humana. A analogia com os problemas teóricos da historiografia parece clara, tornando fundamental a interrogação sobre os diferentes modos 
de representação do passado que tornam a escrita da história uma entre outras práticas humanas de ritualização do poder e do tempo.

Note-se que as questões indicadas, além da relação com uma abordagem do tema da morte atenta à condição histórica do homem como ser dialógico e temporal, também guardam vínculos com a tendência recente de fundir a história da historiografia com a própria epistemologia, já não mais entendida esta última como um saber elaborado "externamente" por "filósofos-epistemólogos" (CATROGA, 2010b, p. 22). Cada vez mais os historiadores têm se afastado da tendência ao estabelecimento de abstrações normativas acerca de como se deve escrever a história em favor da colocação em prática de uma operação investigativa que, visando explicar/ compreender os sentidos conferidos ao passado num presente determinado, permitiria problematizar a própria escrita da história ${ }^{26}$. Não sem razão, tais reflexões seriam retomadas por Fernando Catroga, cujos estudos são caracterizados pela forma específica por meio da qual questões ontológicas se conjugariam com uma atenção à historicidade e às implicações epistemológicas de suas formulações ${ }^{27}$. Nessa perspectiva, o diálogo entre história e filosofia parece assumir uma conformação eminentemente histórica, da mesma forma que aconteceria com outros campos disciplinares, como a antropologia e a sociologia, não desprezados em favor das antigas "filosofias da história"28.

Caberia acrescentar, por outro lado, que, qualquer comparação da historiografia com práticas rituais de simbolização da morte, se estabelecidas a partir das formulações de Michel de Certeau, não poderiam esquecer daquilo que o historiador francês chamaria de "formalidade das práticas", ou seja, as próprias especificidades da história como escrita, caracterizada pela singularidade das operações que, à maneira de deslocamentos e inversões, a estruturam como forma determinada de narrativa (CERTEAU, 1975) ${ }^{29}$. Também não se deveria pressupor que as comparações estabelecidas com ritos mortuários estejam referidas à desconsideração do potencial crítico da historiografia pelo historiador francês, já que, diferentemente de outras práticas memoriais, ela teria por fundamento colocar em questão os recalcamentos que condicionam sua própria fala, não transformando suas lacunas em simples ausências e configurando-se 
na ambivalência de um lugar que se mantêm pela inevitável tensão entre uma partida e uma dívida (CERTEAU, 1975, p. 324). Sempre enfatizando o "imperativo ético e deontológico" que obrigaria o historiador a interrogar-se sobre o que ficou esquecido, desenterrando “[...] os 'esqueletos' escondidos nos armários da memória”, Fernando Catroga, entretanto, parece não ter, ele mesmo, esquecido dessa dimensão crítica, que confere especificidade à escrita da história (CATROGA, 2001, p. 67).

\section{CIVIC CULTS OF THE DEAD AND THE WRITING OF HISTORY: REFLECTIONS ON THE WORK OF FERNANDO CATROGA}

Abstract: Starting from the existence of different theoretical traditions of study on ways of dealing with death, this paper analyzes the reflections by the Portuguese historian Fernando Catroga, indicating how the topic becomes relevant to the theory of history when questioning the relationships between mortuary rites and historiography. It mainly emphasizes the dialogue with specific traditions in the fields of sociology and anthropology, which allow resume deepest philosophical questions about death and historicity from a perspective focused on the specificity of the historical view and its close association with a way to reflect on our own experiences considering the responses given to human existential problems by men of other times and cultures. In this context and in addition to historicity, the problem of otherness becomes the central focus for historiography, which is understood as one among other collective practices of ritualization of time, characterized by the specificity of its critical vocation. Keywords: Cult of the dead. Civic practices. Historicity. Memory. Historiography.

\section{Notas}

${ }^{1} \mathrm{~A}$ análise aqui apresentada faz parte de um estudo mais amplo sobre a história da historiografia da morte, dentro do qual as análises de alguns historiadores são confrontadas com abordagens elaboradas em campos disciplinares diversos. É impossível indicar a extensa bibliografia pertinente ao tema nos limites deste artigo e, por isso, faremos apenas algumas remissões pontuais de modo introdutório. Sobre as dimensões ética e política da primazia conferida à morte do outro, destacam-se, por exemplo, as reflexões de Emmanuel Levinas e Paul Ricoeur (LEVINAS, 1993; RICOEUR, 2012, 2000). Embora não referida diretamente

Anos 90, Porto Alegre, v. 23, n. 44, p. 305-331, dez. 2016 
a Heidegger, pode-se conferir também a valorização da dimensão sociológica por Norbert Elias (ELIAS, 2001). Uma análise de concepções diversas sobre o assunto, inclusive da interpretação heideggeriana em Ser e Tempo, foi elaborada por Marc Crépon (CRÉPON, 2013).

${ }^{2}$ A crítica à ausência do tratamento da leitura freudiana do trabalho de luto por Heidegger foi feita, entre outros, por Jacques Derrida, e é discutida por Marc Crépon (CRÉPON, 2013, p. 105 et seq.). A comparação entre a escrita da história e o trabalho de luto aparece em textos de Ricoeur e Rüsen (RICOEUR, 2000; RÜSEN, 2008, 2003).

${ }^{3}$ A apropriação da linguística pela psicanálise, como na obra de Jacques Lacan, o levaria a definir o símbolo justamente a partir do rito de sepultamento: "Se eu quisesse tomar a questão do símbolo, por outro lado, ao invés de partir da palavra, da fala ou do pequeno feixe, eu partiria da lápide sobre o túmulo do chefe, ou sobre o túmulo de qualquer um. O que caracteriza a espécie humana é justamente cercar o cadáver de algo que constitua uma sepultura, de sustentar o fato de que isso durou. A lápide ou qualquer outro sinal de sepultura merece exatamente o nome de 'símbolo'. É algo humanizante” (LACAN, 2005, p. 36). Uma leitura formidável do tema da morte sob a ótica da psicanálise, valorizadora do imaginário sobre a morte que teria se configurado a partir do primeiro grande conflito mundial, foi elaborada por Sigmund Freud ainda em 1915 (FREUD, 2010).

${ }^{4}$ Desde, pelo menos, os anos 1970 do século passado, um conjunto de textos de autores como Hayden White, Paul Ricoeur, Michel de Certeau, Paul Veyne, entre muitos outros, têm estabelecido um importante debate sobre o problema da imaginação histórica e, portanto, da dimensão poética do trabalho do historiador. Tratando-se de debate enorme e conhecido, torna-se desnecessária uma indicação pormenorizada de referências, destacando-se aqui apenas os textos mais conhecidos dos autores citados (WHITE, 1992; RICOEUR, 2010; CERTEAU, 1975; VEYNE, 1998).

${ }^{5}$ A relação entre os antigos tratados de retórica e as práticas de memorização de uma "arte da memória" foi analisada no importante trabalho de Francis Yates (YATES, 2007). Patrick Hutton tratou das possíveis permanências dessa tradição na escrita histórica (HUTTON, 1993).

${ }^{6}$ No caso de uma antropologia da morte, pode-se destacar como uma referência fundamental os estudos de Louis-Vincent Thomas (1975; 1991; 1985; entre outros). ${ }^{7}$ Parte da tese de doutorado Militância laica e descristianização da morte em Portugal (1865-1911) daria origem ao ao livro O céu da memória: Cemitério romântico e culto cívico dos mortos em Portugal (1756-1911) (1999). Segundo Fernando Catroga, suas preocupações com o tema das comemorações cívicas, entre eles o das práticas de culto dos mortos, surgiram de seus estudos sobre o 
positivismo: "Diria que minha escola nesta matéria foi a 'leitura das fontes' e a eleição de Comte como um sintoma das necessidades que todos os Estados-nação têm de segregar uma religião civil" (CATROGA; FERREIRA, 2009, p. 472). Os estudos de Fernando Catroga sobre o positivismo se iniciaram ainda nos anos 1970, com a apresentação do estudo final de sua licenciatura, que foi publicado, em grande parte, em revistas ligadas à Universidade de Coimbra (CATROGA, 1977a; CATROGA, 1977b).

${ }^{8}$ Uma compilação recente da obra de Catroga foi feita por Sónia Nobre (2015, p. 623-636). Vários foram seus estudos sobre o republicanismo, podendo-se ressaltar, como obra de síntese, O Republicanismo em Portugal: Da formação ao 5 de Outubro de 1910 (2010a).

${ }^{9}$ Foram vários os estudos dedicados a Antero de Quental, parte importante deles reunidos em História, socialismo, política (2001).

${ }^{10}$ Além de Militância laica e descristianização da morte em Portugal (1988) e de O céu da memória (1999), muitas pesquisas parciais sobre o tema do culto dos mortos foram publicadas, podendo-se destacar aqui alguns exemplos (CATROGA, 1997, 2000, 1987, 1986, 1991, 1993).

${ }^{11}$ Fernando Catroga não desprezou o olhar histórico e relativizou a hierarquização entre diferentes modos de tratamento do tema da morte: "Se toda esta fenomenologia tem uma via teorética privilegiada - a analítica existencial (Heidegger, Levinas) -, não são de menor valor, porém, os caminhos abertos pela biologia, pela antropologia cultural, pela etnologia e pela história das mentalidades" (CATROGA, 1999, p. 7).

${ }^{12}$ Fator que explicaria a relação estreita entre a importância conferida à história no Oitocentos e a determinadas práticas memoriais, como o culto cívicos dos mortos. "Ritualizações da história" é o título da parte final do livro História da História em Portugal (CATROGA; TORGAL; MENDES, 1996). O tema da secularização, já presente em Militância laica e descristianização da morte em Portugal (1865-1911), inclusive no que diz respeito à diferença entre este conceito e o de laicização, daria origem a vários textos, com destaque para o extenso Entre Deuses e Césares. Secularização, laicidade e religião civil (2006a). Uma síntese das ideias de Fernando Catroga sobre o tema foi publicada na Revista de História das Ideias (CATROGA, 2004). Conferir também, para as mudanças antes apontadas, além de O Céu da memória (1999), Os passos do homem como restolho do tempo (2009).

${ }^{13} \mathrm{O}$ tema foi tratado nos importantes textos de Jean-Claude Bonnet (BONNET, 1997, 1998).

14 "Como se viu, no significado de pátria, a população e, em certa medida, o território tendem a sobrepor-se à faceta institucional, e a sua funcionalidade é dita numa linguagem lírica, afetiva e maternal, que antropomorfiza, tanto o 
território, transformando-o em paisagem, como a população, que se metamorfoseia numa comunidade fraternal de com/patriotas" (CATROGA, 2008, p. 20). ${ }^{15}$ Referências a Pierre Bourdieu apareceriam em várias obras de Fernando Catroga (por exemplo, CATROGA, 2009, p. 15). A perspectiva de Pierre Bourdieu sobre os ritos de instituição pode ser encontrada no texto Les rites d'institution (BOURDIEU, 2001).

${ }^{16}$ Tratado aqui de forma bastante limitada, tendo em vista a opção por centrarse em algumas ideias principais de Fernando Catroga, o tema da secularização tem sido objeto de um grande debate há décadas, envolvendo uma enorme quantidade de autores, que seria impossível analisar neste artigo. O próprio livro do historiador português já referido, intitulado Entre Deuses e Césares, traz em pormenores elementos centrais do debate, indicando os vários campos de conhecimento e autores a ele relacionados. Além disso, seria importante considerar a diferença estabelecida por Catroga entre "secularização" e "laicização" (CATROGA, 1999, p. 18; 1988, 2004, 2006a).

${ }^{17} \mathrm{O}$ tema da irrupção do novo já estava presente em Caminhos do fim da história, publicação na qual Catroga formulava uma crítica aos diagnósticos pessimistas acerca do fim da História (CATROGA, 2002, p. 220 et seq.).

${ }^{18}$ Sobre a crise dessas instituições, conferir a entrevista de Catroga ao Diário do Nordeste, 9/10/2006, intitulada Secularização e o retorno do religioso.

19 "E, não deixa de ser sintomático que Ricoeur tenha encontrado na teorização de Michel de Certeau sobre a escrita da história uma certeira passagem da 'sepultura-lugar' para a 'sepultura-gesto'” (CATROGA, 2009, p. 39).

${ }^{20}$ Talvez em sentido aproximado possamos compreender a remissão de Fernando Catroga a Walter Benjamin, ressaltando o papel do historiador como o daquele que deveria "salvar o passado" (CATROGA, 2009, p. 45-46).

${ }^{21}$ Fernando Catroga faria uma remissão direta a Paul Ricoeur ao tratar da noção de dívida em relação ao passado (CATROGA, 2009, p. 39). A leitura de Ricoeur sobre as noções de dívida e herança conforme presentes na obra de Heidegger pode ser encontrada em La mémoire, l'histoire, l'oubli (RICOEUR, 2000, p. 472 et seq.).

${ }^{22}$ Além de Ricoeur, Catroga remeteria também ao conceito de re-presentação, de Coolingwood.

${ }^{23}$ Tradução livre.

${ }^{24}$ Refiro-me ao texto Jusqu’a à la mort. Du deuil et de la gaieté, segundo Worms, produzido por volta de 1996, mas publicado apenas postumamente, como a primeira parte do livro Vivant jusqu’a à la mort suivi de Fragments (há tradução para o português, conforme já referido; ver Ricoeur, 2012).

25 "Por um lado, no sentido etnológico e quase religioso do termo, a escrita [da história] desempenha o papel de um rito de enterramento; ela exorciza a 
morte introduzindo-a num discurso. Por outro lado, tem uma função simbolizadora; ela permite a uma sociedade situar-se, conferindo-lhe um passado na linguagem, o que abre um espaço próprio ao presente: 'marcar' um passado é conferir um lugar à morte, mas também redistribuir o espaço dos possíveis, determinar negativamente aquilo que está por fazer e, por consequência, utilizar a narratividade, que enterra os mortos, como meio de fixar um lugar para os vivos" (CERTEAU, 1975, p. 118) (Tradução livre). François Dosse tratou do problema da morte na obra de Michel de Certeau (DOSSE, 2004, p. 99 et seq.). ${ }^{26} \mathrm{O}$ problema foi indicado também em vários estudos de François Hartog, retomados por Fernando Catroga (cf. HARTOG, 2011; CATROGA, 2010b).

${ }^{27} \mathrm{Tal}$ aspecto seria recorrentemente mencionado nas análises de sua obra contidas em livro recentemente publicado. António Pita, por exemplo, ao se referir aos estudos de Catroga sobre a memória, destacava como a História ganharia "uma nova dimensão ontológica" e a "historiografia uma nova dimensão epistemológica" (PITA, 2015, p. 16). Para Temístocles Cezar: "Sua reflexão sobre a condição histórica não é um mero artifício retórico com a intenção de encobrir uma empiria de dados definidos a priori. Antes, a desarmonia epistemológica expressa na suposta distinção entre 'teoria' da história e 'prática' historiográfica encontra na obra de Catroga antídotos que imunizam o leitor deste vício quase indomável que contamina o meio acadêmico" (CEZAR, 2015, p. 272).

${ }^{28}$ A perspectiva histórica de compreensão da filosofia por Catroga foi analidada também por Paulo Archer de Carvalho (CARVALHO, 2015, p. 77 et seq.). Tal fato explicaria a citação de Roger Chartier retomada por Catroga: "Inquietação que nunca será gratuita, porque, para um historiador, pensar a relação entre as duas disciplinas [a filosofia e a história], é, antes de mais, colocar uma questão inteiramente prática e útil: em quê e como a reflexão filosófica permite elaborar melhor os problemas para os quais apontam, nos nossos dias, todo o trabalho histórico concreto e empírico? (Roger Chartier, 1988)" (CATROGA, 2010b, p. 21). Ainda segundo Catroga: "[...] convoca-se os historiadores para um convívio proveitoso com a filosofia - não estamos a escrever, com a filosofia da história [...] E deve lembrar-se que, quando a reflexão é muito externa, ela chega sempre demasiadamente tarde à prática que quer fundamentar. Por conseguinte, aconselha-se a epistemologia do historiador a estar em sintonia com a própria operação historiográfica e não ser uma espécie de prova póstuma da sua consciência crítica" (CATROGA, 2010b, p. 22-23, grifo do autor).

${ }^{29}$ Nesse caso, seria importante considerar também a "formalidade das práticas" dos rituais, aspecto do qual se aproximou, por exemplo, Paul Connerton, ao enfatizar uma retórica dos rituais (CONNERTON, 1999). 
Culto cívico dos mortos e escrita da história:...

\section{Referências}

ARENDT, Hannah. Entre o passado e o futuro. São Paulo: Perspectiva, 2005. . Sobre a revolução. São Paulo: Companhia das Letras, 2011.

ASSMANN, Aleida. Espaços da recordação: formas e transformações da memória cultural. Campinas: Unicamp, 2011.

BONNET, Jean-Claude. Les morts illustres: Oraison funèbre, éloge académique, nécrologie. In: NORA, Pierre (Dir.). Les lieux de mémoire. La Nation. L’idéel. La Gloire. Paris: Gallimard, 1997. p. 1831-1854.

. Naissance du Panthéon: Essai sur le culte des grands hommes. Paris: L’Esprit de la Cité; Fayard, 1998.

BOURDIEU, Pierre. Langage et pouvoir symbolique. Paris: Seuil, 2001.

CANDAU, Joël. Memória e identidade. São Paulo: Contexto, 2011.

. Antropologie de la mémoire. Paris: PUF, 1996.

CARVALHO, Paulo Archer de. Filosofia, anamnésis e história: Uma vi(d)a da sagesse. In: GARNEL, Rita; OLIVA, João Luís (Org.). Tempo e história, ideias e políticas: estudos para Fernando Catroga. Coimbra: Almedina, 2015. p. 73-88.

CATROGA, Fernando. Os inícios do positivismo em Portugal: o seu significado político-social. Revista de História das Ideias, Coimbra, v. 1, p. 287-394, 1977a.

. Os inícios do positivismo na consolidação da ideologia republicana em Portugal. Biblios, Coimbra, v. 53, p. 285-327, 1977 b.

. A cremação na época contemporânea e a dessacralização da morte: o caso português. Revista de História das Ideias, Coimbra, v. 8, p. 223-268, 1986.

. Laicização e democratização da necrópole em Portugal (1756-1911). Cultura, História e Filosofia, v. 6, p. 453-504, 1987.

. Militância laica e descristianização da morte em Portugal (1865-1911). 1988. Tese (Doutorado em Letras)-Faculdade de Letras, Universidade de Coimbra, Coimbra, 1988.

. Revolução e secularização dos cemitérios em Portugal: Inumistas e cremacionistas. In: COELHO, António Matias (Coord.). Atitudes perante a Morte. Coimbra: Minerva, 1991. p. 95-176.

Morte romântica e religiosidade cívica. In: MATTOSO, José. História de Portugal: O Liberalismo. v. 5. Lisboa: Círculo de Leitores, 1993. p. 545-561.

. Heterodoxias e resistências no último rito de passagem: os funerais civis antes da República. Ler Histórias, n. 33, p. 115-140, 1997.

Anos 90, Porto Alegre, v. 23, n. 44, p. 305-331, dez. 2016 
CATROGA, Fernando. O céu da memória: cemitério romântico e culto cívico dos mortos em Portugal (1756-1911). Coimbra: Minerva, 1999.

. A monumentalidade funerária como símbolo de distinção social. In: OS BRASILEIROS de Torna-Viagem. Lisboa: Comissão Nacional para as Comemorações dos Descobrimentos Portugueses, 2000. p. 453-504.

. Memória e História. In: PESAVENTO, Sandra Jatahy. Fronteiras do Milênio. Porto Alegre: Editora da UFRGS, 2001a. p. 43-69.

. Antero de Quental: História, socialismo, política. Lisboa: Editorial Notícias, 2001b.

. Caminhos do fim da História. Revista de História das Ideias, Coimbra, v. 23, p. 131-234, 2002.

. Secularização e laicidade: uma perspectiva histórica e conceptual. Revista de História das Ideias, Coimbra, v. 25, p. 51-127, 2004.

. Entre Deuses e Césares: secularização, laicidade e religião civil. Uma perspectiva histórica. Coimbra: Almedina, 2006a.

. Ainda Será a História Mestra da Vida? Estudos Ibero-Americanos, Porto Alegre, v. 32, n. 2, p. 7-34, 2006b. Edição especial.

. Pátria, nação e nacionalismo. In: TORGAL, Luís Reis; PIMENTA, Fernando Tavares; SOUSA, Julião Soares (Org.). Comunidades imaginadas: Nação e Nacionalismos em África. Coimbra: Imprensa da Universidade de Coimbra, 2008. p. 9-39.

. Os passos do homem como restolho do tempo: Memória e fim do fim da história. Coimbra: Almedina, 2009.

. O Republicanismo em Portugal: da formação ao 5 de outubro de 1910. Lisboa: Casa das Letras, 2010a.

. O valor epistemológico da história da história. In: RIBEIRO, Maria Manuela Tavares (Coord.). Outros combates pela história. Coimbra: Imprensa da Universidade de Coimbra, 2010b. p. 21-47.

CATROGA, Fernando; TORGAL, Luis Reis; MENDES, José Amado. História da História em Portugal: Séculos XIX-XX. Lisboa: Círculo de Leitores, 1996.

CATROGA, Fernando; FERREIRA, Marieta de Moraes. Entrevista a Fernando Catroga. Revista Brasileira de História, São Paulo, v. 29, n. 58, p. 469-487, dez. 2009. CERTEAU, Michel de. L'écriture de l'histoire. Paris: Gallimard, 1975.

. Lacan: une éthique de la parole. In: . Histoire et psychanalyse.

Entre science et fiction. Paris: Gallimard, 2002. p. 239-268. 
Culto cívico dos mortos e escrita da história:...

CEZAR, Temístocles. Varnhagen não leu Capistrano: Ensaio sobre uma experiência narrativa (anacrônica). In: GARNEL, Rita; OLIVA, João Luís (Org.). Tempo e história, ideias e políticas: estudos para Fernando Catroga. Coimbra: Almedina, 2015. p. 271-288.

CONNERTON, Paul. Como as sociedades recordam. Lisboa: Celta, 1999.

COUTINHO, Tiago. Secularização e o retorno do religioso. Diário do Nordeste, 9 out. 2006. Caderno 3.

CRÉPON, Marc. The thought of death and the memory of war. Minneapolis: University of Minnesota Press, 2013.

DOSSE, François. História e Ciências Sociais. São Paulo: Edusc, 2004.

DREIZIK, Pablo (Org.). Lévinas y lo político. Buenos Aires: Prometeo Libros, 2014.

ELIAS, Norbert. A solidão dos moribundos, seguido de Envelhecer e morrer. Rio de Janeiro: Zahar, 2001.

FREUD, Sigmund. Considerações atuais sobre a guerra e a morte (1915). In: . Introdução ao narcisismo: ensaios de metapsicologia e outros textos (19141916). São Paulo: Companhia das Letras, 2010. p. 209-246. (Obras Completas). HARTOG, François. Evidência da História: o que os historiadores veem. Belo Horizonte: Autêntica Editora, 2011.

HUTTON, Patrick. History as an art of memory. Hanover: University of Vermont, 1993.

KOSELLECK, Reinhart. Monumentos a los caídos como lugares de fundación de la identidade de los supervivientes. In: Modernidad, culto a la muerte y memoria nacional. Madri: Centro de Estudios Políticos y Constitucionales, 2011a. p. 65-101.

. La transformación de los monumentos políticos a los caídos en el siglo XX. In: Modernidad, culto a la muerte y memoria nacional. Madri: Centro de Estudios Políticos y Constitucionales, 2011b. p. 103-128.

. Futuro passado. Contribuição à semântica dos tempos históricos. Rio de Janeiro: Contraponto; PUC-Rio, 2006.

LACAN, Jacques. O seminário, livro 7: a ética da psicanálise. Rio de Janeiro: Zahar, 1997.

. Nomes-do-Pai. Rio de Janeiro: Zahar, 2005.

LEVINAS, Emmanuel. Dieu, la mort et le temps. Paris: Éditions Grasset \& Fasquelle, 1993. 
LORAUX, Nicole. A invenção de Atenas. Rio de Janeiro: Editora 34, 1994.

NOBRE, Sónia. Bibliografia essencial de Fernando Catroga. In: GARNEL, Rita; OLIVA, João Luís (Org.). Tempo e história, ideias e políticas: estudos para Fernando Catroga. Coimbra: Almedina, 2015. p. 623-636.

PITA, António Pedro. Fim da história, tempo e experiência. In: GARNEL, Rita; OLIVA, João Luís (Org.). Tempo e história, ideias e políticas: estudos para Fernando Catroga. Coimbra: Almedina, 2015. p. 61-72.

RICOEUR, Paul. Tempo e narrativa. São Paulo: Martins Fontes, 2010. 3 v.

. Vivo até a morte. Do luto e do júbilo. In: Vivo até a morte, seguido de Fragmentos. São Paulo: Martins Fontes, 2012. p. 1-51.

. La mémoire, l'histoire, l'oubli. Paris: Seuil, 2000.

RÜSEN, Jörn. Emotional forces in historical thinking: some metaphorical reflections and the case of mourning. Historein, v. 8, p. 41-53, 2008.

. Mourning by History: ideas of a new element in historical thinking. Historical East and West, v. 1, n. 1, p. 13-38, 2003.

THOMAS, Louis-Vincent. Anthropologie de la mort. Paris: Payot, 1975. 1991.

. La mort en question: traces de mort, mort des traces. Paris: L'Harmattan, . Rites de mort: Pour la paix des vivants. Paris: Fayard, 1985.

URBAIN, Jean-Didier. L'Archipel des Morts: Le sentiment de la mort et les dérives de la mémoire dans les cimitières d'Occident. Paris: PLON, 1989.

. La société de conservation: Étude sémiologique des cimetières d'Occident. Paris: Payot, 1978.

VEYNE, Paul. Como se escreve a história; Foucault revoluciona a história. Brasília, DF: UnB, 1998.

WHITE, Hayden. Meta-história: A imaginação histórica no século XIX. São Paulo: Edusp, 1992.

WORMS, Frédéric. Vie, mort et survie dans et après. La Mémoire, l'Histoire, l'Oubli. In: DOSSE, François; GOLDENSTEIN, Catherine (Dir.). Paul Ricoeur: penser la mémoire. Paris: Seuil, 2013. p. 135-147.

YATES, Francis. $A$ arte da memória. Campinas: UNICAMP, 2007.

Recebido em: 17/12/2015

Aprovado em: 20/05/2016 